\title{
Informal Peer-Assisted Learning Groups Did Not Lead to Better Performance of Saudi Dental Students
}

\author{
Maha AbdelSalam ${ }^{a}$ Maha El Tantawi ${ }^{b}$ Asim Al-Ansari ${ }^{b}$ Adel AlAgl ${ }^{b}$ \\ Fahad Al-Harbic \\ Departments of a Biomedical Dental Sciences, ${ }^{\mathrm{b}}$ Preventive Dental Sciences, and ${ }^{\mathrm{C} S u b s t i t u t i v e ~ D e n t a l ~ S c i e n c e s, ~}$ \\ College of Dentistry, University of Dammam, Dammam, Saudi Arabia
}

\section{Significance of the Study}

- In this study, students with previous high grades benefited to a greater extent from working in peerassisted learning (PAL) groups than others. Similarity of teammates in PAL groups was not associated with better scores. Instructors should consider this when planning group activities, and students should be advised of how grouping patterns are related to academic performance.

\section{Keywords}

Study groups . Undergraduate dental students . Peer-assisted learning · Social network analysis . Academic performance $\cdot$ Learning analytics

\begin{abstract}
Objectives: To describe peer-assisted learning (PAL) groups formed by dental undergraduate students in a biomedical course and to investigate the association of individual and group characteristics with academic performance. Subjects and Methods: In 2015, 92 fourth-year students (43 males and 49 females) in the College of Dentistry, University of Dammam, Saudi Arabia, were invited to form PAL groups to study a unit of a biomedical course. An examination was used to assess their knowledge after 2 weeks. In addition, a questionnaire and social network analysis were used to investigate (1) individual student attributes: gender, role, subject matter knowledge, grade in previous year, teaming with friends,
\end{abstract}

previous communication with teammates, and content discussion, and (2) group attributes: group teacher's previous grade, number of colleagues with whom a student connected, teaming with friends, similarity of teammates' previous grades, and teacher having higher previous grades than other teammates. Regression analysis was used to assess the association of examination scores with individual and group attributes. Results: The response rate was $80.4 \%$ (74 students: 36 males and 38 females). Students who previously scored grades $A$ and $B$ had higher examination scores than students with grades C/less (regression coefficient $=18.50$ and 13.39) within the groups. Higher scores were not associated with working in groups including friends only (regression coefficient $=1.17$ ) or when all students had similar previous grades (regression coefficient $=0.85$ ). Conclusions: Students with previous high grades benefited to a greater extent from working in PAL groups. Similarity of teammates in PAL groups was not associated with better scores.

C 2017 S. Karger AG, Basel

\section{KARGER}

E-Mail karger@karger.com www.karger.com/mpp
(C) 2017 S. Karger AG, Basel

Karger

This is an Open Access article licensed under the terms of the Creative Commons Attribution-NonCommercial 3.0 Unported license (CC BY-NC) (www.karger.com/OA-license), applicable to the online version of the article only. Distribution permitted for non-commercial purposes only.
Prof. Maha El Tantawi

Department of Preventive Dental Sciences, College of Dentistry University of Dammam, PO Box 1982, Dammam Coastal Road

Dammam 31441 (Saudi Arabia)

E-Mail maha_tantawy@hotmail.com 


\section{Introduction}

Standards in health professional education promote self-learning and team work to prepare students for their professional life [1]. In peer-assisted learning (PAL), individuals from similar backgrounds, who may not necessarily be teachers, help each other to learn by teaching [2] in a reciprocal learning activity [3]. PAL helps individuals to develop knowledge and skills when they share perspectives that lead to constructive understanding and differs in outcome from that if individuals were on their own [4]. This phenomenon can be explained by the social constructivist learning theory [4] and by the occurrence of cooperative learning where students work together to achieve a common objective [5]. PAL is useful to academic institutions, since it offers opportunities to reduce faculty teaching load and fills gaps in the curriculum [68]. It also helps students develop communication and professional skills and provide support to each other with less stress compared to that felt in the presence of experts $[7,9]$.

In most cases, the groups in PAL are instructor-formed where instructors assign students to groups with specific tasks. Studies have shown that PAL had positively perceived and actual effects on learning when the groups are instructor-formed and supervised, whether they are nursing [10] or medical students [11, 12]. The outcomes of instructor-formed student groups did not significantly differ from those taught by teaching staff [13], and students considered their peers to be more important to success in examination than experts [14].

Alternatively, students may form groups that are not organized by educational institutions or instructors [15]. In this type of learning, students spend time in contact with each other inside or outside the classroom. Exchange of information and sharing of experience helps learning - even in the absence of explicit planning by instructors [15]. Equally important, Denson et al. [16] reported a learning experience of a student-formed group that was useful in developing their mathematical modeling skills.

Social network analysis (SNA) focuses on networks that include units/nodes (such as students) connected by links/edges (such as shared PAL study group membership) $[17,18]$. The SNA techniques were previously used to study the communication patterns and interaction of students in health professional education with each other and with their instructors, including postgraduate nursing students [19] as well as medical students, residents, and faculty $[18,20]$. In these different studies, SNA proved to be a useful tool, demonstrating changing networks by time patterns of active versus passive communication [19, 20] and preferences in selection of friends [18].

It would be useful to understand the characteristics of dental student-formed groups that are not under direct instructor supervision. This includes how students select their teammates and whether or not their individual and group attributes are related to subsequent academic performance. Therefore, the aims of the study were (a) to describe the structure and attributes of student-formed groups as arranged by dental undergraduates without direct supervision of instructors to address a didactic unit in a biomedical course and (b) to investigate the association between the individual and group attributes regarding academic performance.

\section{Subjects and Methods}

\section{Setting and Participants}

The study was conducted at the College of Dentistry, University of Dammam, Saudi Arabia, in 2015-2016. The college offers a Bachelor of Dentistry program in 6 years. The first year is preparatory and includes basic sciences. Years 2 and 3 cover basic medical and preclinical dental courses. Students start clinical training in the 4th year. Male and female students are segregated in conformance with cultural norms. They are taught the same content by the same teachers using the same teaching and assessment methods, where lectures are repeated at different times in separate sessions for each gender. The Institutional Review Board approved the study.

Oral Pathology is taught in 2 courses: 3 rd and 4 th years. The present study included part of the 4th-year 3-credit Oral Pathology I course. The course has 1 weekly hour of instructor-delivered lectures and $3 \mathrm{~h}$ of weekly session where histopathologic features of oral diseases and conditions are discussed. The course was selected because it is didactic and does not address psychomotor skills, and thus covers learning outcomes corresponding to those targeted by the study. In addition, the students were midway through the college program and could be expected to have already formed social networks with their colleagues.

Inclusion criteria were students in Oral Pathology I course, who agreed to work in PAL groups to study the assigned unit and fill the study questionnaire. There were 92 students (43 males and 49 females) participating in the course.

\section{Intervention}

Instructors selected the same unit in the Oral Pathology course (epithelial tumors) for both male and female students. Students were asked to form PAL study groups and were given the freedom to select their teammates in groups of 2-4 students. Each class formed their own study groups independently so that there were exclusively male and female groups. In each student-formed group, the students agreed that one of them would be teacher who studied on his/her own and then explained the content while the remaining students would be learners who received the information delivered by the student teacher. They were given the course learning resources and 2 weeks to interact and study on their own 


\begin{tabular}{|c|c|c|c|c|}
\hline & Males & Females & All & $p$ value \\
\hline & $\therefore$ & $\infty \int_{0}^{\infty}$ & & \\
\hline Groups & 13 & 11 & 24 & \\
\hline Mean number per group & $2.8 \pm 0.8$ & $2.9 \pm 2.6$ & - & 0.45 \\
\hline Degree of relationship & 1.306 & 1.500 & - & - \\
\hline Groups with all friends & $8(61.5)$ & $8(72.7)$ & $16(66.7)$ & 0.56 \\
\hline Groups with similar previous grades & $2(15.4)$ & 7 (63.6) & $9(37.5)$ & $0.02^{*}$ \\
\hline Groups with teachers of higher grades & $6(46.2)$ & $4(36.4)$ & $10(41.7)$ & 0.63 \\
\hline
\end{tabular}

Fig. 1. Networks of student-formed study groups of 4 th-year dental students. Nodes represent students with previous year grades: green represents students with grade $\mathrm{A}$, yellow with grade $\mathrm{B}$, and red with grade $\mathrm{C} /$ less. Nodes representing student teachers are larger in size. Pink links are connections between friends; black links are connections between nonfriends. Data are presented as $n(\%) .{ }^{*} p \leq 0.05$. away from class and instructor supervision. Males and females formed 13 and 11 study groups, respectively (Fig. 1) with an average of 3 students in each group (average 2.8 and 2.9 in male and female groups, respectively). A student directly connected to 1-2 other students (degree $=1.306$ and 1.500). In 16 groups, all students were friends, with 10 groups having student teachers of higher grades than learners. In more female than male groups, members had similar previous grades (7 compared to 2).

After 2 weeks, knowledge was objectively assessed using a written examination of 22 multiple choice questions. Eighteen questions assessed recall (such as selecting the correct term to describe pathologic features) and 4 questions assessed higher cognitive skills (such as providing differential diagnosis for clinical and histopathologic features). The questions were automatically using Optical Mark Recognition machines. At the end of the study, the instructor explained the scientific material in a formal class setting. The material was reassessed within the course assessment scheme so that the student-formed group examination scores were not included in the course total grade.

\section{Study Tool}

Students responded to a questionnaire which asked whether or not they had previous knowledge of the subject matter, were learners or teachers during the experience, and the grade they scored in the previous year (A, B, or $\mathrm{C} /$ less). The questionnaire also collected information assessing various forms of interaction as previously described [21,22]. Thus, for each of the other students in the group, a respondent was asked to indicate (1) whether he/she was considered a friend (targeting the effect of diffusion of knowledge through already existing social networks [23]), (2) whether there was prior communication between the respondent and the teammate before the study (addressing the effect of existing channels for information transfer when there was no strong social tie through friendship), and (3) whether there was discussion of the content with this teammate in and out of class (to assess the effect of focused communication targeting the assigned task). The instructors explained the questionnaire to the students, waited until they filled it, and collected it during the same session.

\section{Analysis}

The $\chi^{2}$ test was used to compare individual attributes of male and female students (role, grade in previous year, previous knowledge of subject matter, teaming with friends, previous frequency of communication, and discussing subject matter). The groups' networks were visualized using the Gephi open source software [24] with layouts "force atlas" and "no overlap" and undirected edges. Gephi was used to calculate the "degree," which is the average number of colleagues with whom a student directly teamed [23]. It was also used to assign group attributes (formerly group of friends with similar previous grades and student teacher grades compared to learners in the groups). Linear regression was used to investigate individual and group attributes associated with percent score in the examination. Attributes with statistically significant association in univariate regression were entered into 2 types of multivariate models: (a) model 1 - all individual attributes in one model and group attributes in another model, and (b) model 2 - individual and group attributes together adjusted for gender. Partial $\eta^{2}$ was used to estimate effect size. Regression coefficients and $95 \%$ confidence intervals were calculated using SPSS version 20.0. Significance level was set at $p \leq 0.05$.

\section{Results}

Of the 92 students participating in the course, 74 responded to the questionnaire (response rate $=80.4 \%$ ). Of these, $36(48.6 \%)$ were males and 48 (64.9\%) learners (Table 1). A significantly higher proportion of females (20, $52.6 \%)$ than males $(6,16.7 \%)$ had A grades in the previous

Informal Peer-Assisted Learning and 
Table 1. Description of students participating in the study groups

\begin{tabular}{|c|c|c|c|c|}
\hline & Males & Females & All & $p$ value \\
\hline Students & $36(48.6)$ & $38(51.4)$ & $74(100)$ & \\
\hline \multicolumn{5}{|l|}{ Role } \\
\hline Learner & $22(61.1)$ & $26(68.4)$ & $48(64.9)$ & \multirow[t]{2}{*}{0.51} \\
\hline Teacher & $14(38.9)$ & $12(31.6)$ & $26(35.1)$ & \\
\hline \multicolumn{5}{|l|}{ Grade last year } \\
\hline A & $6(16.7)$ & $20(52.6)$ & $26(35.1)$ & \multirow[t]{3}{*}{$<0.001$} \\
\hline $\mathrm{B}$ & $21(58.3)$ & $18(47.4)$ & $39(52.7)$ & \\
\hline C/less & $9(25)$ & 0 & $9(12.2)$ & \\
\hline \multicolumn{5}{|c|}{ Already knew the subject matter } \\
\hline Yes & $17(47.2)$ & $24(63.2)$ & $41(55.4)$ & \multirow[t]{2}{*}{0.17} \\
\hline No & $19(52.8)$ & $14(36.8)$ & $33(44.6)$ & \\
\hline \multicolumn{5}{|l|}{ Group members } \\
\hline Friends & $28(77.8)$ & $32(84.2)$ & $60(81.8)$ & \multirow[t]{2}{*}{0.48} \\
\hline Not friends & $8(22.2)$ & $6(15.8)$ & $14(18.9)$ & \\
\hline \multicolumn{5}{|c|}{ Frequent past communication with group members } \\
\hline Yes & $24(66.7)$ & $35(92.1)$ & $59(79.7)$ & \multirow[t]{2}{*}{0.01} \\
\hline No & $12(33.3)$ & $3(7.9)$ & $15(20.3)$ & \\
\hline \multicolumn{5}{|c|}{ Discussion in and out of class } \\
\hline Yes & $7(19.4)$ & $11(28.9)$ & $18(24.3)$ & \multirow[t]{2}{*}{0.34} \\
\hline No & $29(80.6)$ & $27(71.1)$ & $56(75.7)$ & \\
\hline
\end{tabular}

Values are $n(\%)$.

year $(p<0.001)$. Of the 74 respondents, $41(55.4 \%)$ reported that they had previous knowledge of the subject matter with no significant difference between males and females $(p=0.17)$. Sixty $(81.8 \%)$ and $18(24.3 \%)$ reported discussing the content in and out of class with no significant differences between males and females, respectively ( $p=0.48$ and 0.34$)$. More females $(92.1 \%, 35 / 38)$ reported frequent previous communication with group members than males $(67 \%, 24 / 36)$, and the difference was statistically significant $(p=0.01)$.

The mean score in the unit examination was $65.5 \pm$ $13.9 \%$. Univariate regression showed that this score was associated with individual student attributes (grade in previous year and teaming with friends; Table 2) with both retaining significance when considered together in model 1 ( $p=0.01$ and 0.03 ); also, group attributes showed a significant association with examination score (degree and belonging to a group where the teachers had higher previous grades than the learners) with only the latter attribute retaining significance when considered in model 1 . Among the individual and group attributes, the greatest effect was that of students' previous grades (partial $\eta^{2}=0.13$ and 0.08 for students previously scoring $A$ and $\mathrm{B}$, respectively). The effect of teaming with friends was greater than the effect of group attributes (degree and be- longing to a group where student teachers had higher grades) (partial $\eta^{2}=0.05,0.02$, and 0.003 ). The attribute with significance in model 2 was students' previous grades: regression coefficient $(95 \% \mathrm{CI})=18.50$ (5.54, $31.46)$ and $13.39(1.05,25.73)$ for A and B compared to C students. The adjusted mean scores of the students were $65.80 \pm 3.05(95 \% \mathrm{CI}=58.43,73.32), 60.74 \pm 2.44(95 \%$ $\mathrm{CI}=54.61,66.92)$, and $47.32 \pm 5.75(95 \% \mathrm{CI}=35.53$, 59.23), with statistically significant differences between $A$ and $C$ students $(p=0.02)$ and no significant differences between A and B or B and C students (0.52 and 0.10).

\section{Discussion}

In this study, students with previous high grades benefitted most from working in PAL, similar to the finding of Hommes et al. [23] and Donohoe et al. [25] who had reported that past academic performance had the greatest effect on future performance. Equally, being a teacher or a learner was not significantly associated with scores. This finding confirmed the previous reports $[25,26]$ in which medical students who acted as PAL tutors did not perform better overall than others with a similar background where academic abilities were considered [26].
340

Med Princ Pract 2017;26:337-342 DOI: $10.1159 / 000477731$
AbdelSalam/El Tantawi/Al-Ansari/AlAgl/ Al-Harbi 
Table 2. Attributes associated with unit examination percent score

\begin{tabular}{|c|c|c|c|c|}
\hline & \multicolumn{3}{|c|}{ Regression coefficient $(95 \% \mathrm{CI})$} & \multirow[t]{2}{*}{ Partial $\eta^{2}$} \\
\hline & univariate model & multivariate model 1 & multivariate model 2 & \\
\hline \multicolumn{5}{|l|}{ Individual attributes } \\
\hline Males vs. females & $-3.20(-9.91,3.50)$ & & & \\
\hline Learners vs. teachers & $-3.39(-10.26,3.49)$ & & & \\
\hline Previous knowledge of subject matter & $3.38(-3.34,10.10)$ & & & \\
\hline Student's grade last year: A vs. C/less & $21.74(10.24,33.23)^{*}$ & $20.69(8.47,32.90)^{*}$ & $18.50(5.54,31.46)^{*}$ & 0.13 \\
\hline Student's grade last year: B vs. C/less & $15.13(3.96,26.30)^{*}$ & $14.99(3.10,26.89)^{*}$ & $13.39(1.05,25.73)^{*}$ & 0.08 \\
\hline Discussing content in and out of class vs. not & $3.43(-4.24,11.10)$ & & & \\
\hline Teaming with friends vs. not & $11.48(2.31,20.65)^{*}$ & $9.77(1.11,18.43)^{*}$ & $6.10(-5.12,17.32)$ & 0.05 \\
\hline $\begin{array}{l}\text { Communicating rarely with group members } \\
\text { previously vs. not }\end{array}$ & $-2.94(-12.94,7.07)$ & & & \\
\hline \multicolumn{5}{|l|}{ Group attributes } \\
\hline Group teacher's grade last year: A vs. C/less & $10.26(-1.44,21.95)$ & & & \\
\hline Group teacher's grade last year: B vs. C/less & $8.68(-3.20,20.55)$ & & & \\
\hline $\begin{array}{l}\text { Average number of colleagues a student was connected } \\
\text { to (degree) }\end{array}$ & $2.13(0.03,4.23)^{*}$ & $1.61(-0.54,3.77)$ & $1.10(-1.10,3.30)$ & 0.02 \\
\hline Working in group made up exclusively of friends & $1.17(-5.86,8.19)$ & & & \\
\hline $\begin{array}{l}\text { Working in group with similar grades among all } \\
\text { teammates in previous year }\end{array}$ & $0.85(-6.20,7.89)$ & & & \\
\hline $\begin{array}{l}\text { Working in groups with teachers of higher grades than } \\
\text { learners }\end{array}$ & $-12.10(-21.35,-2.86)$ & $-10.72(-20.06,-1.39)$ & $-4.66(-15.14,5.82)$ & 0.003 \\
\hline
\end{tabular}

In this study, group characteristics had less effect on scores than individual attributes, as shown by the scores which were not associated with grades of other students in the same group and were negatively affected if PAL teachers had higher scores. These findings were different from those of Woolf et al. [27] who reported that friendship at baseline among medical students predicted subsequent score similarity. The difference between the 2 studies could be attributed to learners in our study overestimating the advantage of being in a group with top students, and thus exerting less effort to studying and thereby depriving themselves of the advantage of PAL.

The association of univariate regression between scores and having at least 1 friend among the students in the PAL group of this study confirmed the previous report that friendship binds colleagues [28] and provided a supportive network in academic environments through sharing of knowledge and learning resources [23, 29]. The finding that discussing the topic in and out of class and a history of frequent past communication among group members were not associated with score is different from a study which indicated an association between examination score and mutual communication among 1st-year medical students [23]. The difference could be attributed to the fact that the depth and frequency of the reported discussion was not assessed in the present study. This study showed that the examination score was not associated with the degree of relationship among students. This finding also differed from a study where the degree of relationship was associated with academic success [30]. This difference could be attributed to the small number of students per group in the current study.

The limitations of this study were the inclusion of only 1 class, the nature of studies using SNA that focuses on the particular network, the use of students' reports that were dependent on their completeness, and gender segregation.

\section{Conclusions}

In this study, examination scores were associated with individual attributes to a greater extent than group attributes, with previous academic performance being the key attribute. This study demonstrated the usefulness of SNA as a learning analytics tool to understand PAL and student-formed group structure in comparison with individual attributes in association with subsequent academic performance. 


\section{References}

1 Commission on Dental Accreditation, American Dental Association: Accreditation standards for dental education programs, 2013. http://www.ada.org/ /media/CODA/ Files/ predoc.ashx (accessed June 10, 2016).

2 Goodlad S: Mentoring and Tutoring by Students. London, Kogan, 1998, pp 1-7.

3 Boud D, Cohen R, Sampson J: Peer Learning in Higher Education: Learning from and with Each Other. London, Kogan, 2001, p 4.

4 Vygotskii LS: Mind in Society: The Development of Higher Psychological Processes. Cambridge, Harvard University Press, 1978, pp 84-90.

5 Johnson DW, Johnson R: Learning Together and Alone: Cooperative, Competitive, and Individualistic Learning, ed 5. Boston, Allyn \& Bacon, 1999, pp 3-5.

6 Ten Cate O, Durning S: Dimensions and psychology of peer teaching in medical education. Med Teach 2007;29:546-552.

7 Yu TC, Wilson NC, Singh PP, et al: Medical students-as-teachers: a systematic review of peer-assisted teaching during medical school. Adv Med Educ Pract 2011;2:157-172.

8 Perkins GD, Hulme J, Bion JF: Peer led resuscitation training for healthcare students: a randomised controlled study. Intensive Care Med 2001;28:698-700.

9 Hurley KF, McKay DW, Scott TM, et al: The supplemental instruction project: peer devised and delivered tutorials. Med Teach 2003;25:404-407.

10 Zentz SE, Kurtz CP, Alverson EM: Undergraduate peer-assisted learning in the clinical setting. J Nurs Educ 2014;53:S4-S10.

11 Clarke AJ, Burgess A, Menezes A, et al: Senior students' experience as tutors of their junior peers in the hospital setting. BMC Res Notes 2015;8:743.
12 Han ER, Chung EK, Nam KI: Peer-assisted learning in a gross anatomy dissection course. PLoS One 2015; 10:e0142988.

13 Knobe M, Münker R, Sellei RM, et al: Peer teaching: a randomised controlled trial using student-teachers to teach musculoskeletal ultrasound. Med Educ 2010;44:148-155.

14 Tayler N, Hall S, Carr NJ, et al: Near peer teaching in medical curricula: integrating student teachers in pathology tutorials. Med Educ Online 2015;20:27921.

15 Gerber BL, Cavallo ML, Edmund AM: Relationships among informal learning environments, teaching procedures and scientific reasoning ability. Int J Sci Educ 2001;23:535549 .

16 Denson C, Lammi M, White TF, et al: Value of informal learning environments for students engaged in engineering design. J Tech Stud 2015;41:40-46.

17 Ruane R, Koku EF: Social network analysis of undergraduate education student interaction in online peer mentoring settings. MERLOT J Online Learn Teach 2014;10:577-589.

18 Hafferty FW, Castellani B, Hafferty PK, et al: Anatomy and histology as socially networked learning environments: some preliminary findings. Acad Med 2013;88:1315-1323.

19 Merrill JA, Yoon S, Larson E, et al: Using social network analysis to examine collaborative relationships among $\mathrm{PhD}$ and DNP students and faculty in a research-intensive university school of nursing. Nurs Outlook 2013;61: 109-116.

20 Walton JM, Steinert Y: Patterns of interaction during rounds: implications for work-based learning. Med Educ 2010;44:550-558.
21 Bruun J, Bearden IG: Time development in the early history of social networks: link stabilization, group dynamics, and segregation. PLoS One 2014;9:e112775.

22 Grunspan DZ, Wiggins BL, Goodreau SM: Understanding classrooms through social network analysis: a primer for social network analysis in education research. CBE Life Sci Educ 2014;13:167-178

23 Hommes J, Rienties B, de Grave W, et al: Visualising the invisible: a network approach to reveal the informal social side of student learning. Adv Health Sci Educ Theory Pract 2012;17:743-757.

24 Gephi: The open graph wiz platform. https:// gephi.org (accessed March 3, 2017).

25 Donohoe CL, Conneely JB, Zilbert N, et al: Docemur docemus: peer-assisted learning improves the knowledge gain of tutors in the highest quartile of achievement but not those in the lowest quartile. J Surg Educ 2015;72: 1139-1144.

26 Iwata K, Furmedge DS, Sturrock A, et al: Do peer-tutors perform better in examinations? An analysis of medical school final examination results. Med Educ 2014;48:698-704.

27 Woolf K, Potts HW, Patel S, et al: The hidden medical school: a longitudinal study of how social networks form, and how they relate to academic performance. Med Teach 2012;34: 577-586.

28 Lovell B: "We are a tight community": social groups and social identity in medical undergraduates. Med Educ 2015;49:1016-1027.

29 Cho H, Gay G, Davidson B, et al: Social networks, communication styles, and learning performance in a CSCL community. Comp Educ 2007;49:309-329.

30 Divjak B, Peharda P: Social network analysis of study environment. J Inform Organ Sci 2010;34:67-80. 